\title{
Economics of Climate Smart Agriculture: An Overview
}

\author{
Nancy McCarthy, Leslie Lipper, and David Zilberman
}

\begin{abstract}
Climate change, especially through greater frequency and intensity of climate extremes, is expected to negatively impact agriculture and food security, particularly in developing countries highly dependent on rain-fed agriculture. Promoting growth and food security must draw on the rich literature of the past 50-60 years while also addressing potential structural shifts in the factors that promote growth. This paper summarizes the economic considerations of Climate Smart Agriculture, a concept developed by the FAO to address the complex issue of how to achieve sustainable agricultural growth for food security under climate change. It addresses the lack of coherence on the CSA approach by building a formal basis of the CSA concept and methodology. We do this by posing a dynamic optimization problem wherein a social planner seeks to maximize expected discounted welfare associated with agriculture of the population they serve, both now and in the future. We analyze constraints, choices, and features of design of CSA to illustrate on the concept can be applied across a range of locations and conditions. This has implications for research, innovation, and policy design.
\end{abstract}

\section{Introduction}

Climate change is expected to have negative impacts on agriculture and food security in many regions, particularly in developing countries highly dependent on rainfed agriculture. The fifth assessment report of the IPCC released in 2014 found that climate change effects are already being felt on agriculture and food security, and

\footnotetext{
N. McCarthy $(\bowtie)$

Lead Analytics Inc., Washington, DC, USA

e-mail: nmccarthy@leadanalyticsinc.com

L. Lipper

ISPC-CGIAR, Rome, Italy

e-mail: leslie.lipper@fao.org

D. Zilberman

Department of Agriculture and Resource Economics, University of California Berkeley,

Berkeley, CA, USA

e-mail: zilber11@berkeley.edu
} 
the negative impacts are most pronounced in tropical zones where most of the world's poor and agricultural-dependent populations are located (IPCC 2012). And yet in the next 20 years, increasing the rate of agricultural growth in these regions is essential to reach the goals of eradicating poverty and meeting growing food demand associated with population growth and dietary transitions.

Over the last 50-60 years, a rich and extensive body of work on agricultural development economics has been developed, aimed at supporting agricultural growth and food security. Over time this work has been augmented with insights and techniques from natural resource and environmental economics, as well as behavioral and institutional economics. The evidence base has also expanded dramatically due to advancements in empirical research design, econometric techniques, data availability and computing power. At the same time, the public sector has invested in agricultural and rural development, accumulating practical experience and knowledge.

Climate change, with its potentially transformative impacts on agricultural systems, means that we need to revisit the key tenets of this accumulated body of knowledge and experience in order to identify its applicability to current and changing circumstances. Does climate change actually require a change in how we go about planning and investing in agricultural growth for food security and poverty reduction? The answer is not obvious - much research and policy design in agricultural development has been concerned not only with enhancing productivity, but also with reducing negative environmental impacts and providing public goods, as well as managing trade-offs between risk and returns and reducing vulnerability of farm households to a wide array of shocks. These are also some of the major concerns raised, perhaps to a more urgent level, with respect to addressing climate change in agriculture. However we need to consider whether the potential magnitude and scale of climate change will result in a structural shift in the factors that will promote growth - and thus how we go about promoting growth and food security.

The increased frequency and intensity of extreme events is clearly one of the most important game-changing effects of climate change. Recent work by Fischer and Knutti (2015) on the link between climate change and extreme events estimated that $75 \%$ of extreme hot days and $18 \%$ of days with heavy rainfall worldwide can be explained by the warming we've seen over the industrial period. The same study also finds that the probability of extreme events increases nonlinearly with increasing global warming. For instance, the probability of an extreme hot day under a scenario of $2{ }^{\circ} \mathrm{C}$ increase over pre-industrial levels is almost double the probability at a $1.5^{\circ} \mathrm{C}$ increase, and is more than five times higher than with today's climate. Essentially, the vulnerability of the agricultural sector to adverse events is increasing at a rapid, steep and broad scale, which implies a need for innovative measures to reduce the exposure and sensitivity of the agricultural sector, and also to increase adaptive capacity.

Greater frequency and intensity of climate extremes has implications for research, innovation, and policy design. With respect to research, though the empirical evidence on households' responses to weather shocks is fairly large, most of the data 
collected has been undertaken under relatively normal weather conditions, with spatially limited idiosyncratic weather shocks. Thus, little is known about the impacts of generalized climate shocks on households' wellbeing, and even less is known about which mechanisms are most effective at minimizing those impacts. Additionally, evidence is lacking on which measures are most effective at increasing the resilience of the agricultural sector as a whole. Part of the problem is the lack of capacity to mobilize resources needed to collect relevant data in the immediate wake of disasters that occur at significant scale, as well as logistical, and potentially ethical, issues involved with collecting data under such circumstances. Valuable information could be obtained by those involved in disaster relief activities, but such information is generally not collected in a systematic manner nor widely shared. As noted by Scott et al. (2016), though everyone agrees that monitoring and evaluation (M\&E) should be a critical element in disaster relief, most M\&E systems remain weak and data collected remains little shared.

With respect to innovation and policy design, increased frequency and intensity of climate extremes dramatically increases the value of innovations and policies that increase the range of cost-effective options that allow rapid adjustments in the face of climate extremes. This implies a need for a strong shift towards investing in technological and institutional innovations that create options and increase flexibility. This also implies a need for designing policies and regulations that enable different actors - including government agencies as well as the private sector - to exercise various options in response to climate extremes.

The second potential game-changer arises from the possibility of major regional shifts in weather patterns, or "migration" of climate. This effect may be due to spatially and seasonally heterogeneous increases in average temperature and altered rainfall patterns. Such changes may have major consequences in terms of movement of pests and diseases, as well as loss of coastal and certain inland agricultural lands. We can expect that migration of climate will disproportionately affect resource-poor and marginalized farmers who have less adaptive capacity but depend primarily on agriculture for their livelihoods (Hitz and Smith 2004; Thornton et al. 2011). Experience has indicated that intensifying labor migration is a common response to prolonged and chronic environmental degradation, with permanent resettlement less common and generally considered less desirable. However this option is increasingly considered as an adaptation strategy in response to major shifts, such as sea level rise. Current empirical evidence indicates that the poor and most vulnerable to climate risks are again the least capable to undertake effective migration, since they lack the assets and social networks required (Adger et al. 2014; Taylor and Martin 2001).

Successfully adapting to emerging major shifts in weather means that research needs to focus on which factors facilitate the transition to new climate patterns while maintaining growth rates and reducing poverty. Research is needed to evaluate both adaptive, marginal changes within the system to confront such shifts, as well as far-reaching transformational changes. Research is also needed to generate sufficient evidence to compare the relative merits of pursuing incremental adaptation strategies versus transformational strategies. For instance, access to new crop 
varieties, more suitable livestock, irrigation systems, and pest management strategies can enable farmers to successfully adapt to new climate patterns. At the same time, enabling farm households to relocate may well be a better strategy, especially under more extreme shifts in climate patterns. While there is a fair amount of household-level research on internal and international migration and its impacts on migrant households, much less is known about which institutional structures and mechanisms best support peaceful relocations. While processes of movement in and out of agriculture are ongoing (Taylor and Martin 2001), future research should aim to understand the institutional challenges and planning requirements to address climate related migration within ongoing population transition processes.

More broadly, the interaction between climate change induced changes in agricultural production patterns and structural transformation in the larger food system and rural non-farm sectors need to be better understood (c.f. Haggblade et al. 2007; Reardon and Timmer 2007; Gollin et al. 2002). Given the systems-level focus of such research, this calls for greater integration of sub-discipline research, e.g. linking agro-ecosystem or agri-food sector-wide models with evidence from household surveys. To date, however, such models capture institutional structures and mechanisms in a fairly rudimentary way. While institutions are important for understanding marginal changes, they are particularly important for understanding and promoting transformational changes. ${ }^{1}$ Large-scale household surveys and randomized experiments will be of limited value in answering many key questions about systems-level outcomes and optimal institutional structures and mechanisms. Instead improved methodologies for analyzing limited data, e.g. using case studies across disciplines will be required, echoing recommendations of Reardon and Timmer (2007) with respect to agrifood systems.

A third major transformation climate change imposes on agricultural development planning is the need to decouple agricultural growth from emissions growth, given the high share of agriculture in contributing to global emissions. World Resource Institute (WRI) estimated that emissions from agriculture could grow from approximately 6.5 GT in 2010 to $9.5 \mathrm{GT}$ per year in 2050 under a conventional agricultural growth strategy. At the same time, the development of the nationally appropriate mitigation actions (NAMAs) and Intended Nationally Determined Contributions (INDCs), has shown that developing countries are interested in pursuing low-emissions agricultural growth strategies, if financing to support such actions can be made available. Reducing emissions from the agricultural sector requires technologies and practices to increase efficiency and reduce leakage from agricultural production systems, and also enhance the sequestration capacity of the sector by increasing trees and shrubs. Improved soil management, sustainable rice intensi-

\footnotetext{
${ }^{1}$ Certain institutional mechanisms are relatively well-studied, such as various aspects of property rights. The impacts of increased access to institutions has also been well-studied but mostly in a rudimentary way, e.g. dummy variables capturing access to a health care center, credit, extension, etc. But, specific delivery mechanisms, the range of services offered, service quality, contract clauses etc. are much less well-studied. Such information is crucial to policy design. New research tools and methods are needed to help build this evidence base.
} 
fication, precision farming, and restoration of degraded lands can all contribute to reduced GHG emissions and/or soil carbon sequestration under certain conditions (Burney et al. 2010; Lal 2004; Paustian et al. 2004; Antle and Diagana 2003). But, as many researchers have documented, there has been limited adoption of sustainable land management (SLM) practices that could also contribute to a low-emissions agricultural growth path, particularly in sub-Saharan Africa and parts of Southeast Asia (Barbier 2010; Pender et al. 2006; Barrett et al. 2002).

In terms of research, there is a great deal of evidence on the benefits to adopting SLM, but much less evidence on the costs and barriers that farmers face in adopting such practices (McCarthy et al. 2012; Pender et al. 2006; Nkonya et al. 2004). Given these costs and barriers, there is a need for the public sector to develop innovative policies and mechanisms that alter incentives for actors in the agricultural sector to pursue such strategies. One mechanism that has received a great deal of attention is a carbon-sequestration based payment (Seeberg-Elverfeldt et al. 2009). However, such programs often fail because of the difficulty in monitoring and verifying compliance, and with making and enforcing contracts with, and delivering payments to, many smallholders (Lockie 2013; Alix-Garcia et al. 2012; Cacho et al. 2005). Research needs to shift towards generating better evidence on a wider range of specific institutional structures and mechanisms that link smallholders to financing opportunities, including expanding the innovative use of information and communication technologies (ICTs) and geo-spatial information. This type of evidence is critical if poor smallholders are to benefit from international mitigation financing. At the country level, many governments are still leery of promises of mitigation financing - and the bureaucracy and conditionalities it brings - and there is a clear need to refine the international institutional mechanisms associated with such financing.

To summarize, the need to address an unprecedented level and magnitude of uncertain change poses a challenge to economic analyses aiming to support agricultural growth and food security, particularly as these changes will clearly differ across regions. Research that will identify methods to improve agricultural resource allocation and management strategies to address emerging climate change patterns, as well as empirical research that will identify the effectiveness of existing management tools in addressing some of the early manifestations of climate change, will be of high value. This research needs to be part of multidisciplinary efforts needed to expand the feasible set of technologies and agronomic management practices, explicitly accounting for decision-making under uncertainty. In addition to technologies and management practices aimed at the farm level, research will also be needed to assess the net benefits from investments in public infrastructure and services, and to evaluate the potential benefits from creating or reforming laws and regulations critical to the agricultural sector, such as those related to public and private land use, as well as the finance, communications and insurance sectors. Research is also needed to understand the role of key institutions in meeting growth objectives while minimizing negative impacts of climate change and securing GHG reductions where possible, and what new institutional forms may be required. Land tenure and property rights, water rights, extension and weather information dissemination services, cooperatives and farmers' unions, and credit and insurance markets 
are but a few such key institutions. Finally, we emphasize that the responses to climate change may consist both of incremental adaptation, primarily based on scaling up existing technologies and modifying institutions, laws and regulations, and transformative adaptation, including new institutions and major reallocation of resources over space and time. These responses vary in their time dimension and are interdependent (Nelson et al. 2007).

Since policy planning addresses multiple objectives, such as higher incomes, more stable incomes, and lower emissions, one of the key areas of focus is highlighting potential trade-offs in meeting multiple objectives. The goal is to be able to evaluate which policy actions can ameliorate trade-offs and harness synergies amongst the multiple objectives. The latter is particularly important since meeting increasing global food demand and local food security objectives requires continued growth in the agricultural sector. There are a number of potential trade-offs that can arise due to impacts from climate change. For instance, increased frequency of extreme weather events increases the value of policy actions that reduce household vulnerability to such events, but may also compromise strategies to enhance average growth levels of agricultural productivity and farmer incomes. Similarly, policies and public investments to address uncertain longer-term shifts in weather patterns can shift resources away from addressing current poverty alleviation goals. Pursuing low-emissions growth strategies can also involve trade-offs with near-medium term growth objectives, which need to be clearly understood - and externally financed in order to avoid placing additional burdens on smallholders in developing countries.

Understanding the potential impacts of climate extremes and shifting climate patterns and evaluating how different options and strategies can best address these is a complicated process. As a beginning step, the Climate Smart Agriculture (CSA) concept was developed in order to address the complex issue of how to achieve sustainable agricultural growth for food security under climate change (FAO 2009, 2010; Lipper et al. 2014). The concept calls for integration of the need for adaptation and the possibility of GHG mitigation in agricultural growth and poverty reduction strategies. However there is considerable confusion about what the CSA concept and approach actually involve, and wide variation in how the term is used. At this time, it is critical to build a more formal basis for the CSA concept and methodology and at the same time provide illustrations of how the concept can be applied across a range of conditions. This is the primary focus of this book.

\section{CSA: The Objectives of the Social Planner}

The design of CSA can be analyzed as an economic decision-making problem from the perspective of a social planner. We will not solve the problem formally, but will identify its main features and some of the characteristics of potential solutions. The social planner is concerned with optimizing the welfare of the population they serve, both now and in the future. CSA then is a way of laying out this dynamic 
optimization problem and its constraints that explicitly incorporates effects of climate change. A plausible objective is maximization of expected discounted welfare associated with agriculture, from a basket of "goods" provided by agriculture. Of course, the agricultural sector is but one sector in the economy, and as noted above, the best option may be to help people transition out of agriculture. Thus, while we emphasize the agricultural sector, other sectors are clearly important. Welfare is comprised of several components. Here we focus on the four pillars of food security: food availability, access, utilization (e.g. food safety), and stability of food supplies. Stability of food supplies is related both to household-level vulnerability as well as resilience of the agricultural system. ${ }^{2}$ Finally, we can include environmental objectives, including the global objective to reduce GHG emissions growth as well as local objectives related to improved land quality and water resource management.

The dynamic nature of the optimization problem captures potential trade-offs between choices to improve welfare now versus choices made now to improve welfare under uncertain future outcomes. It also highlights the impacts of uncertainty on decisions made now, and thus the value of additional information and/or the value of choices that increase the flexibility to adapt as more information becomes available. A dynamic framework also enables us to evaluate costs and benefits associated with alternative "weather-migration" scenarios and lower emissions growth strategies.

\section{The Constraints Facing the Social Planner}

When deciding on the extent and means of pursuing avenues for improving welfare outcomes, the social planner must take into consideration constraints in the form of biophysical relationships and behavioral, institutional and political constraints. The biophysical relationships consist of several elements. First is the production function, which links outputs to ecological inputs and weather. One of the key challenges in designing agricultural policies is in understanding the heterogeneous impacts of climate change on productivity. Furthermore, modeling of the production function needs to consider both continuous as well as discrete variables. This approach allows us to investigate technology adoption in response to climate change (Mendelsohn and Dinar 1999; Antle and Capalbo 2010; Arslan et al. 2015). Understanding the stochastic nature of the production function, particularly due to weather realizations, will also be important in designing programs, such as insurance and inventory, to address the challenges of climate change. The second biophysical element is the externality function, which expresses the relationships between economic activities and the various externalities generated by them

\footnotetext{
${ }^{2}$ We basically adopt the IPCC WGII AR5 definitions of vulnerability and resilience, as provided in Appendix 1. However, for conceptual convenience, we are defining vulnerability as a householdlevel characteristic, and resilience as a system-level characteristic.
} 
(Zilberman 2014). In the context of CSA, the greenhouse gas emissions are the main, but not sole, externality considered. Various agricultural practices and investments also generate both positive and negative local externalities. Overuse of inorganic fertilizer generates greenhouse gas emissions and can also pollute local water sources (Norse 2012). Investment in soil and water conservation structures at the farm and ecosystem levels can generate positive spillover benefits to neighboring farmland productivity (Mirzabaev et al. 2015; McCarthy et al. 2012). Without effective coordination and collective action, too few positive spillovers, and too many negative spillovers, will be generated.

In analyzing both the production and externality functions, we recognize that agriculture is very diverse, and different sectors of agriculture (e.g. irrigated agriculture, rain-fed agriculture, etc.) will experience climate change differently. Livestock husbandry and fisheries will have unique challenges as well, and our analysis should strive to provide appropriate solutions that recognize specific contexts.

The behavioral constraints include market choices made by risk-averse individual agents (both inputs and outputs) operating in contexts where insurance markets are very thin or entirely absent. Our analysis will emphasize the importance of climate conditions on the supply and demand of various goods. The choices will be dependent on risk preferences and market conditions, as well as government policies. An important category of behavioral choices relates to decisions regarding technology adoption, including irrigation, seed varieties and production practices. Almost all empirical evidence suggests that uninsured risk and uncertainty leads to low levels of adoption of new technologies, and this behavioral constraint must be addressed if hoped-for wide-scale adoption is to be realized (Antle and Crissman 1990; Dercon and Christiansen 2011). Furthermore, adopting any new technology is often itself seen to be risky by the farmer who faces uncertainty about its performance (Foster and Rosenzweig 2010). Zilberman et al. (2012) note that, in addition to risk preferences, the diffusion of technology adoption as an adaptation to climate change will also be a function of heterogeneity in farmers' access to capital, the underlying agro-ecology, and prevailing institutions that can foster or hinder adoption.

Technology adoption and institutional innovations are also a function of political constraints. As Hayami and Ruttan (1971) emphasize, innovations of new technologies are outcomes of economic choices that are responsive to incentives and policies. Thus, the literature on innovation also emphasizes the role of learning in innovation and the evolution of new technologies, which in turn affect adoption. Political economic modeling suggests that government policy is affected by economic conditions as well as environmental and political considerations (Buchanan and Tollison 1984; Shepsle 1992; Rausser et al. 2011). These suggest that individual government policy choice problems are derived from their own political economy constraints so that the decision to implement policies that favor certain technologies over others will be a function of this political calculus. Where political weighting favors high economic growth, for instance, the technologies promoted may conflict both with resilience and low-emissions growth goals, for instance. 
In addition to political economy considerations, additional political constraints will bound the range of feasible policy and legal actions to address climate change. Some policy solutions to climate change may not be politically feasible, and realistic policy design must consider feasibility of solutions within various local and global contexts. For example, it will be politically easier and it makes common sense to enact policies that improve human well-being and welfare regardless of climate change. A no-regret constraint may bind the set of policies that would be valuable under certain future conditions to those that also address pressing issues of food security or sustainable land use, thereby satisfying distributional and environmental objectives.

The institutional constraints include input, output and labor markets, property rights and tenure security, information dissemination systems such as agriculture extension and weather forecasting, credit and insurance markets and their regulatory framework, social safety net programs, environmental regulations, and the international trading system and local import, export, and foreign direct investment regulations. The institutional environment has a significant impact on farmers' incentives and ability to invest in agriculture practices with CSA characteristics and to adapt to climate change. Thin value supply chains limit farmers' ability to access inputs in timely fashion, and sell their output at a profit. Integrated supply chains can significantly reduce market price swings in response to extreme weather events, thereby reducing vulnerability of rural households to poor crop output and high food prices (Reardon and Timmer 2007). As discussed above, thin or absent credit markets, often combined with very limited insurance mechanisms, dampen incentives to make any types of investment on-farm, and limits the choices available to risk-averse farmers to adapt. Similarly, property rights systems that result in tenure insecurity also limit incentives to invest in land (Mirzabaev et al. 2015; Holden et al. 2009).

The ability to adapt to climate change will also be affected by the information dissemination system and farmers' ability to access weather forecasts and longerterm climate predictions and to incorporate that information into adaptation and coping strategies. Additionally, improving the resilience of the agricultural system as a whole will necessitate making investments and coordinating changing practices at scales higher than the household level. The ability to invest in larger-scale infrastructure to improve the resilience of a watershed (Bassist et al. forthcoming), or coordinating investments in tree planting or check dams across many small communities will depend on local property rights, land use regulations and powers of eminent domain, as well as environmental regulations. The ability to coordinate actions across communities will also be affected by collective active institutions and local-level governance structures (Meinzen-Dick et al. 2004; Pender et al. 2006). The ability to relax institutional constraints will be key in reducing household vulnerability and increasing system resilience in many contexts.

The optimization problem has several dynamic constraints as well. The first constraint is the dynamics of climate change. Because of the nature of agriculture, it is important to have an adequate assessment of climatic variation over space and time in 
order to make predictions of yields and outputs. There is much uncertainty in climate modeling and it must be incorporated into policy design. Thus, it is not sufficient to get average predictions of climatic patterns over time, but also some indication of variability and reliability thereof. Uncertainty of weather patterns is important because as Dixit and Pindyck (2001) suggested, the pattern and levels of uncertainty delay the optimal timing of investment. With uncertainty, decision-makers value additional information and are willing to wait some time for more information, which can lead to significant delays in investments. This compounds risk-averse farmers' disincentives to invest in land or adopt new technologies.

A second dynamic element is population growth, which affects demand for food as well as urbanization patterns, both of which are important determinants of optimal agricultural growth pathways. Human population growth is also behavioral to some extent and thus population dynamics must take account of behavioral parameters. Furthermore, population dynamics are subject to uncertainty so we must consider outcomes under several scenarios in assessing and designing climate change policies.

The third dynamic element is the ongoing transition in agriculture associated with globalization and the spread of information and technological advances. Global supply chains are spread everywhere, and the expanded use of the internet, cell phones, and improved transportation mechanisms are likely to continue. Technological change is especially important given the role of innovation and adoption in adaptation to climate change, but its diffusion will be a function of both political constraints as well as the need to adapt technologies to site-specific characteristics. One also needs to understand the workings of the supply chain innovations in different regions and how they can be utilized to introduce new technologies in response to climate change. While further integration and connectivity can increase agricultural system resilience by reducing, pooling and transferring risks, positive results will nonetheless be a function of the international and national level regulatory frameworks. To achieve food security objectives, such frameworks need to incorporate regulations that limit monopolistic/oligopolistic power and instead harness the risk-reducing benefits for everyone in the agricultural system, as well as effective enforcement mechanisms.

\section{The Social Planner's Choice Set}

Returning to the social planner's problem - to maximize constrained expected welfare - the social planner can take actions at the system level, or actions that alter incentives for farmers and other actors in the agricultural sector to adopt technologies and practices that improve welfare outcomes. With respect to system-level actions, the social planner can invest in providing a wide range of public goods that improve welfare and increase system resilience in the face of climate change, including: investing in CSA research and development; investing 
in large-scale infrastructure projects to increase system resilience to climate extremes and longer-term changes in weather patterns such as irrigation systems and flood control structures; investing in weather information systems; investing in disaster risk management systems, including restructuring social safety-net programs to explicitly incorporate payouts related to climate disasters; and, creating or amending laws and regulations regarding property rights, land use and zoning, contract farming, and insurance markets. At the system-level, improved risk coping measures include the design and implementation of disaster risk management plans at various government scales, rapid repair of damaged infrastructure, and, development of insurance instruments targeted for national and municipal governments.

Reducing household vulnerability and increasing system resilience can be accomplished through expansion and promotion of ex ante risk management strategies and/or ex post coping strategies. At the household level, ex ante risk management strategies include adopting SLM techniques; irrigation; drought, heat and/or flood resistant crop varieties and livestock breeds; and, diversifying land and labor activities. Measures that can be undertaken to improve the capacity of farm households to cope with shocks when they do occur include access to social safety net programs, access to attractive insurance instruments, and access to information and infrastructure to re-allocate labor to less affected areas. With respect to actions that affect farmers' incentives, potential actions include payment for environmental services programs; direct subsidies for adoption of certain investments and/or practices such as irrigation or SLM practices; and subsidies for inputs or participation in insurance schemes.

The social planner can also undertake actions to increase adaptive capacity and to pursue least-cost strategies of adaptation under an uncertain future climate, including the possibility of "weather migration". Adaptive capacity is a function of available risk management and risk coping mechanisms, but also includes broader measures to improve decision-making under uncertainty. Uncertainty increases the value of putting in place sophisticated monitoring and evaluation systems and continual learning (IPCC 2012) Greater adaptive capacity is associated with increasing the range of options to manage climate extremes and potentially changed climate patterns, and increasing the ability to exercise those options when needed. It should be stressed that the ability to exercise options when needed is often as critical as having options to begin with. For instance, many researchers find that it is precisely wealthier farmers who are more able to diversify their income sources, reconfirming longstanding findings in most sub-Saharan African countries (Davis et al. 2014; Arslan et al. 2015). So, allocating labor off-farm in response to a weather shock means not only that there are labor opportunities somewhere in the country, but also that farmers know where those opportunities are, can afford transportation, and have sufficient skills to be hired.

Resilience and adaptive capacity are complementary traits. Greater adaptive capacity can increase a system's capacity to recover from swings in climatic and biophysical conditions. But when the pressures exceed some threshold, adaptive 
capacity can also enable systems to change completely, to adapt through structural transformation, thereby enabling the people to survive and even flourish. Similarly, greater adaptive capacity can enable farm households to reduce vulnerability, but at some point, the best option may be for at least some family members to leave the agricultural sector or diversify their livelihood in order to best adapt to changing climate conditions. At the system-level, adaptive capacity will also be required to address potential mass migration from areas no longer suitable for agricultural production.

The above discussion on adaptive capacity and adaptation captures a major potential trade-off between pursuing strategies that enable farmers to improve their well-being in the face of climate change within the current agricultural system versus strategies that allow for the system itself to change in response to climate change e.g. the difference between incremental and transformative adaptation strategies (Adger et al. 2014). Insurance and safety net payments are classic examples of policies that enable people to better withstand extreme events within the current system. Access to irrigation, improved tenure security, and investments in flood control infrastructure all have similar impacts. In certain circumstances, particularly changes in weather patterns that make current production systems impossible or unprofitable, the social planner will have to determine whether to continue pursuing incremental strategies, or whether to accommodate and manage migration or promote a structural transformation in the production system.

Finally, the social planner can assess opportunities for pursuing low-emissions growth strategies. Certain practices, such as most sustainable land investments and practices, can generate both greater food security and lower emissions, though as noted above, current incentives are too low to foster wide-spread adoption in many countries. Low-emissions growth strategies that pose greater trade-offs with both immediate and long-term food security objectives require international financing, particularly given that most developing countries have contributed very little to cumulative GHG emissions. Where suitable and/or external financing is available, adaptive capacity will need to be built to foster a switch to low-emissions agricultural growth strategies.

\section{Towards a Socially Optimal Solution: Expected Features of Model Outcomes}

Optimizing welfare over multiple objectives that include all four elements of food security and potentially reduced GHG emissions first implies that the impacts of any potential policy action be evaluated for each objective, with the aim of identifying synergies and trade-offs. And, by inserting alternative solutions to this constrained optimization problem, we are able to evaluate their relative merits by comparing the balance of outcomes across a range of objectives from each of these proposed solutions, under a wide range of climate change scenarios. Evaluating outcomes across 
the multiple objectives will highlight the role of weighting these objectives in arriving at a solution, particularly where there are trade-offs. Assigning weights is a necessary step toward defining a socially optimal solution. The modeling exercise provides a framework for highlighting these weighting choices and can thus feed into climate change policy debates at national and international levels.

A second important outcome of this model is the implication that shadow prices of various constraints will allow us to consider alternative policies by changing the constraints and parameters of the system. The most valuable reforms are implied by the solution to the constrained optimization problem and resulting shadow prices. Business-as-usual scenarios can then be contrasted with scenarios under various types of policy reform that relax various constraints, which may induce either incremental or transformative changes.

This formulation provides us a starting point for our analysis and the type of solutions and research needed to inform it. Because of the increased importance of uncertainty, the solution strategy to this problem will involve adaptive learning. The decision makers have the capacity to learn from the past—and improve their estimation of key parameters over time as knowledge is accumulated - so data accumulation and learning will be part of the policy making process, and decision-makers may experiment with various policies to learn more about the system and its constraints. The random pressures on the system give rise to incentives to invest in adaptive capacity - solutions that will allow decision making to respond effectively to a wide range of potential outcomes. Adaptive capacity may include the ability to learn, analyze, and respond effectively. In many situations, it may be through increasing flexibility and adaptability of institutions, capital goods, and the population through enhancing human capital and reducing transactions costs associated with re-allocating resources (e.g. labor, money, goods), including effective information systems that reach all actors in the system.

\section{Concluding Comments}

In this chapter, we have attempted to lay out a conceptual framework to underpin the CSA concept rooted in agricultural development economic theories and concepts. We began by highlighting the key features of climate change that require a shift in emphasis in research, and for innovations in technologies, institutions, and government policies and programs. These changes include: (1) increased frequency and intensity of climate extreme events, with potentially disastrous impacts on already vulnerable smallholders dependent on rainfed agriculture, (2) permanent changes in weather patterns making certain areas unsuitable for agricultural production under existing conditions, and (3) the need to reduce emissions from the agricultural sector as a whole, while ensuring growth in the sector. These changes strongly highlight the need to consider the heterogeneity of impacts and to understand the implications of decision-making under uncertainty. They also point to the increased value of an expanded set of technological and institutional options to deal with both 
heterogeneity and uncertainty, and particularly to the increased value of flexibility broadly understood.

To set the framework, we began by viewing CSA as a welfare optimization problem. The problem has multiple objectives, namely the four pillars of food security, food availability, accessibility, utilization, and stability, as well as reducing emissions growth in the sector as a whole. The problem is also characterized by current constraints that bound the feasible outcomes, including bio-physical, behavioral, political, institutional and distributional constraints. Achieving better outcomes can occur by directly increasing food security, for instance by introducing technologies that increase yields and reduce yield losses in extreme years. Or, better outcomes can be achieved by relaxing key constraints. We also stress that the nature of the optimization, and thus adaptation strategies, are context specific.

Adaptation to climate change may take several forms: innovation and adoption of new technologies, adoption of existing technologies, temporary or permanent migration, changes of agricultural activities and trade patterns, and increased range of attractive and viable insurance products. Adaptation in most cases will also include addressing institutional failures and constraints such as reducing tenure insecurity, increasing access to relevant information, and improving the ability to coordinate actions across a watershed or ecosystem. And, some adaptation strategies will imply a discrete system-level change realized through broad-based structural transformation. While the solution cannot provide the exact changes in technologies or institutions that would result in the best outcomes, it can help to define the characteristics, or principles, associated with improved technologies or highly effective institutional structures and mechanisms.

Finally, we highlight that the solution to the social planner's problem for climate change must balance adaptation and responsiveness to uncertain climate change with the needed growth and food security objectives of the agricultural sector. Weighting the multiple objectives is essentially a political process.

\section{References}

Adger, W.N., J.M. Pulhin, J. Barnett, G.D. Dabelko, G.K. Hovelsrud, M. Levy, Ú. Oswald Spring, and C.H. Vogel. 2014. Human security. In: Climate Change 2014: Impacts, Adaptation, and Vulnerability. Part A: Global and Sectoral Aspects. Contribution of Working Group II to the Fifth Assessment Report of the Intergovernmental Panel on Climate Change [Field, C.B., V.R. Barros, D.J. Dokken, K.J. Mach, M.D. Mastrandrea, T.E. Bilir, M. Chatterjee, K.L. Ebi, Y.O. Estrada, R.C. Genova, B. Girma, E.S. Kissel, A.N. Levy, S. MacCracken, P.R. Mastrandrea, and L.L. White (eds.)]. Cambridge University Press, Cambridge, United Kingdom and New York, NY, USA, pp. 755-791.

Alix-Garcia, J.M., Shapiro, E.N. and Sims, K.R., 2012. Forest conservation and slippage: Evidence from Mexico's national payments for ecosystem services program. Land Economics, 88(4), pp.613-638.

Antle, J.M. and S.M. Capalbo. 2010. Adaptation of agricultural and food systems to climate change: an economic and policy perspective. Applied Economic Perspectives and Policy, doi: 10.1093/aepp/ppq015. 
Antle, J.M. and B. Diagana. 2003. Creating incentives for the adoption of sustainable agricultural practices in developing countries: the role of soil carbon sequestration. American Journal of Agricultural Economics, 85(5): 1178-1184.

Antle, J.M. and C.C. Crissman. 1990. Risk, efficiency, and the adoption of modern crop varieties: Evidence from the Philippines. Economic Development and Cultural Change, 38(3):517-537.

Arslan, A., McCarthy, N., Lipper, L., Asfaw, S., Cattaneo, A. and Kokwe, M. (2015): Climate Smart Agriculture: Assessing the Productivity and Adaptation Implications in Zambia. Journal of Agriculture Economics, 66(3): 753-780.

Barbier, E.B. 2010. Poverty, development, and environment. Environment and Development Economics, 15(06): 635-660.

Barrett, C.B., F. Place, and A. Aboud. 2002. The challenges of stimulating adoption of improved natural resource management practices in African agriculture. In: C. Barrett, F. Place, and A. Aboud (eds), Natural Resources Management in African Agriculture. Nairobi, Kenya: ICRAF and CABI.

Bassist, A., B. Blankespoor, A. Dinar, and S. Dinar. 2017. Assessing Technical, Economic and Policy Aspects of Water Scarcity Using Surface Wetness with Application to the Zambezi, Mekong and Red River Basins. In: L. Lipper, N. McCarthy, D. Zilberman, S. Asfaw, and G. Branca: Climate Smart Agriculture - Building Resilience to Climate Change. New York: Springer.

Buchanan, J.M., and R.D. Tollison. 1984. The Theory of public choice--II. University of Michigan Press.

Burney, J.A., S.J. Davis, and D.B. Lobell. 2010. Greenhouse gas mitigation by agricultural intensification. Proceedings of the national Academy of Sciences, 107(26): 12052-12057.

Cacho, O.J., Marshall, G.R. and Milne, M. 2005. Transaction and abatement costs of carbon-sink projects in developing countries. Environment and Development Economics, 10(05): 597-614.

Davis, B., S. Di Giuseppe, and A. Zezza. 2014. Income Diversification Patterns in Rural SubSaharan Africa: Reassessing the Evidence. World Bank Policy Research Working Paper No. 7108. Available at SSRN.: http://ssrn.com/abstract $=2524162$

Dercon, S., and L. Christiaensen. 2011. Consumption risk, technology adoption and poverty traps: Evidence from Ethiopia. Journal of development economics, 96(2): 159-173.

Dixit, A.K., and R.S. Pindyck. 2001. The options approach to capital investment. Real options and investment under uncertainty: Classical readings and recent contributions, pp. 61-78.

FAO. 2009. Food Security in Agricultural Mitigation in Developing Countries: Options for Capturing Synergies. October, 2009. Rome: FAO.

FAO. 2010. Climate-Smart Agriculture: Policies, Practices and Financing for Food Security, Adaptation and Mitigation. Rome, FAO.

Fischer, E. M., and R. Knutti. 2015. Anthropogenic contribution to global occurrence of heavyprecipitation and high-temperature extremes. Nature Climate Change 5: 560-564, doi:10.1038/ nclimate.

Foster, A.D. and M. R. Rosenzweig. Microeconomics of technology adoption. Annual Review of Economics 2: 2010, doi: 10.1146/annurev.economics.102308.124433.

Gollin, D., Parente, S. and Rogerson, R. 2002. The role of agriculture in development. The American Economic Review, 92(2): 160-164.

Haggblade, S., Hazell, P.B. and Reardon, T. eds. 2007. Transforming the rural nonfarm economy: Opportunities and threats in the developing world. Washington, DC: IFPRI.

Hayami, Y., and V.W. Ruttan. 1971. Agricultural development: an international perspective. Agricultural development: an international perspective. Baltimore, MD/London: The Johns Hopkins Press.

Hitz S., and J. Smith. 2004. Estimating global impacts from climate change. Global Environmental Change (Part A) 14(3): 201-218.

Holden, S.T., K. Deininger, and H. Ghebru. 2009. Impacts of low-cost land certification on investment and productivity. American Journal of Agricultural Economics 91(2): 359-373. 
IPCC. 2012. Managing the Risks of Extreme Events and Disasters to Advance Climate Change Adaptation. A Special Report of Working Groups I and II of the Intergovernmental Panel on Climate Change. Field, C.B., V. Barros, T.F. Stocker, D. Qin, D.J. Dokken, K.L. Ebi, M.D. Mastrandrea, K.J. Mach, G.-K. Plattner, S.K. Allen, M. Tignor, and P.M. Midgley (eds.). Cambridge, UK, and New York, NY: Cambridge University Press.

Lal, R. 2004. Soil carbon sequestration impacts on global climate change and food security. Science 204: 1623-1627.

Lipper, L., P. Thornton, B.M. Campbell, T. Baedeker, A. Braimoh, M. Bwalya, P. Caron, A. Cattaneo, D. Garrity, K. Henry, R. Hottle, L. Jackson, A. Jarvis, F. Kossam, W. Mann, N. McCarthy, A. Meybeck, H. Neufeldt, T. Remington, P. Thi Sen, R. Sessa, R. Shula, A. Tibu, and E. Torquebiau. 2014. Climate-smart agriculture for food security. Nature Climate Change, 4(12): 1068-1072.

Lockie, S. 2013. Market instruments, ecosystem services, and property rights: assumptions and conditions for sustained social and ecological benefits. Land Use Policy, 31: 90-98.

McCarthy, N., L. Lipper, and G. Branca. 2012. Climate-smart agriculture: smallholder adoption and implications for climate change adaptation and mitigation. Mitigation of Climate Change in Agriculture Working Paper 3.

Meinzen-Dick, R., M. DiGregorio, and N. McCarthy. 2004. Methods for studying collective action in rural development. Agricultural systems 82(3): 197-214.

Mendelsohn, R., and A. Dinar. 1999. Climate change, agriculture, and developing countries: does adaptation matter? The World Bank Research Observer 14(2): 277-293

Nelson D.R., W.N. Adger and K. Brown. 2007. Adaptation to environmental change: contributions of a resilience framework. Annual Review Environment and. Resources, 32:395-419.

Norse, D. 2012. Low Carbon Agriculture: Objectives and Policy Pathways. Environmental Development, 1(1): 25-39.

Nkonya, E., J. Pender, P. Jagger, D. Sserunkuuma, C. Kaizzi, and H. Ssali. 2004. Strategies for sustainable land management and poverty reduction in Uganda. Research Report 133. Washington, DC: IFPRI.

Paustian, L., B. Babcock, J.L. Hatfield, R. Lal, B.A. McCarl, S. McLaughlin, A. Mosier, C. Rice, G.P. Roberton, N. Rosenberg, and C. Rosenzweig. 2004. Agricultural mitigation of greenhouse gases: science and policy options. In: 2001 Conference Proceedings, First National Conference on Carbon Sequestration. Washington, DC: Conference on Carbon Sequestration.

Pender, John, Frank Place, and Simeon Ehui, eds. 2006. Strategies for sustainable land management in the East African highlands. Washington, DC: IFPRI.

Rausser, G.C., J. Swinnen, and P. Zusman. 2011. Political power and economic policy: theory, analysis, and empirical applications. Cambridge, UK and New York, NY: Cambridge University Press.

Reardon, T. and C.P. Timmer. Transformation of markets for agricultural output in developing countries since 1950: How has thinking changed? Handbook of agricultural economics, 3(2007): 2807-2855.

Scott, Z., Wooster, K., R. Few, A. Thomson, and M. Tarazona. 2016. Monitoring and evaluating disaster risk management capacity. Disaster Prevention and Management 25 (3): 412-422.

Seeberg-Elverfeldt, C., S. Schwarze, and M. Zeller. 2009. Payments for environmental servicesCarbon finance options for smallholders' agroforestry in Indonesia. International Journal of the Commons, 3(1).

Shepsle, K.A. 1992. Congress is a "they," not an "it": Legislative intent as oxymoron. International Review of Law and Economics 12(2): 239-256.

Taylor, J.E. and P.L. Martin. 2001. Human capital: Migration and rural population change. Handbook of agricultural economics, 1(2001): 457-511.

Thornton, P.K., P.G. Jones, P.J. Ericksen, and A.J. Challinor. 2011. Agriculture and food systems in sub-Saharan Africa in a $4^{\circ} \mathrm{C}+$ world. Philosophical Transactions of the Royal Society A: Mathematical, Physical and Engineering Sciences 369(1934):117-136. 
Zilberman, D., Jinhua Zhao, and Heiman, A. 2012. Adoption versus adaptation, with emphasis on climate change. Annual Review of Resource Economics, 4(1): 27-53.

Zilberman, D. 2014. The economics of sustainable development. American Journal of Agricultural Economics, 96 (2): 385-396.

Open Access This chapter is distributed under the terms of the Creative Commons AttributionNonCommercial-ShareAlike 3.0 IGO license (https://creativecommons.org/licenses/by-nc-sa/3.0/ igo/), which permits any noncommercial use, duplication, adaptation, distribution, and reproduction in any medium or format, as long as you give appropriate credit to the Food and Agriculture Organization of the United Nations (FAO), provide a link to the Creative Commons license and indicate if changes were made. If you remix, transform, or build upon this book or a part thereof, you must distribute your contributions under the same license as the original. Any dispute related to the use of the works of the FAO that cannot be settled amicably shall be submitted to arbitration pursuant to the UNCITRAL rules. The use of the FAO's name for any purpose other than for attribution, and the use of the FAO's logo, shall be subject to a separate written license agreement between the FAO and the user and is not authorized as part of this CC-IGO license. Note that the link provided above includes additional terms and conditions of the license.

The images or other third party material in this chapter are included in the chapter's Creative Commons license, unless indicated otherwise in a credit line to the material. If material is not included in the chapter's Creative Commons license and your intended use is not permitted by statutory regulation or exceeds the permitted use, you will need to obtain permission directly from the copyright holder.

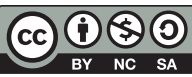

